\title{
Influence of vegetation on the propagation of flood waves
}

\author{
L. De Doncker ${ }^{1}$, R. Verhoeven ${ }^{1}$, P. Troch ${ }^{1}$, N. Desmet ${ }^{2,3}$, \\ P. Meire ${ }^{2}$ \& P. Seuntjes ${ }^{3}$ \\ ${ }^{1}$ Hydraulics Laboratory, Department of Civil Engineering, \\ Ghent University, Belgium \\ ${ }^{2}$ Ecosystem Management Research Group, \\ University of Antwerp, Belgium \\ ${ }^{3}$ Flemish Institute for technological Research, VITO, Mol, Belgium
}

\begin{abstract}
Research on river ecosystems asks for a multidisciplinary approach. All components such as water, macrophytes, sediment, suspended solids, etc. play an important role. The presence of macrophytes in rivers has an influence on water levels and flow patterns since a wealthy vegetation growth causes back water effects and consequently higher upstream water levels. In view of this, flood risk increases in periods of higher flows and greater vegetation growth. So, river management also deals with the control of vegetation. Good management contributes not only to the quality of the water and the ecosystem, but also to flood protection.
\end{abstract}

Keywords: backwater effect, ecological modelling, vegetated rivers.

\section{Introduction}

In many lowland rivers in Flanders, a significant increase in macrophyte growth has been observed. This is due to eutrophication and a better water quality (Vereecken et al. [1]) of surface water, which is imposed by the European Union and laid down in the 'Water Framework Directive' (2000/60 EG). The directive aims at a better water quality by structural interventions in rivers. A better water quality influences the macrophytes (increasing growth) and so, the drainage of the river. Therefore, the ecological and hydraulic function of the macrophytes has to be understood. The vegetation influences the roughness of the channel bed 
and banks which, as a major modelling parameter, is important for the prediction of floods since aquatic plant growth can lead to a substantial rise of the water level (Aminal [2]), (NVVE [3]). The channel roughness can be expressed by the Manning coefficient.

By this, there is a relation between the amount of biomass in and the discharge capacity of the river. Good river management includes mowing of vegetation to avoid floods, with respect to the ecological functions of the river. Therefore, a well-considered choice of mowing patterns is essential to balance both requirements.

\section{Study area and data set}

\subsection{The river Aa}

Focus of the study is the downstream part of the river Aa. The catchment basin of the river $\mathrm{Aa}$ is situated in the region of Antwerp in Belgium and is hydrographically part of the Nete basin. The most important rivers of this basin are the Kleine Nete and the Grote Nete, both influenced by the tidal bore. More than $40 \%$ of the water in the Nete basin is carried by the river Aa, which is consequently the most important tributary of the Kleine Nete. It has a total length of $36.8 \mathrm{~km}$ and a drainage area of about $23700 \mathrm{ha}$. The study area is focused on the downstream part of the Aa, on a $1.4 \mathrm{~km}$ reach controlled by two weirs at the up-and downstream end.

The river Aa is a typical lowland river with low velocities, a small fall and a strongly meandering character. Over the years, the river has been straightened and the section was enlarged. The water inflow originates from drainage of rain water and seepage of ground water. The water is rather acid, without chalk and a low amount of minerals, not suitable for organisms. Living conditions for them are caused by food supply in the way of organic drainage of fertilizers from the fields of agriculture along the banks of the river.

\subsection{Hydraulic measurements}

Discharge was monthly measured from a bridge and from a boat in different sections along the stretch under concern in the period from September 2004 to May 2007. The method used is the integration of the velocity field over the cross section as is explained in (Herschy [4]) Two devices are used for measuring the velocity of the water. In case of open water (no vegetation), hydrometric propellers (Type: OTT, C31 Universal Current Meter) are used, while in locations where vegetation might hinder the mechanical functioning of the propeller an electromagnetic instrument (Type OTT, Nautilus C2000/SENSA Z300 and Valeport, Type 801) is applied.

\subsection{Biomass collection}

In the river Aa, macrophytes found are various leaved water-starwort (Callitriche platycarpa), rigid hornwort (Ceratohyllm demersum) and floatingleaf pondweed (Potamogeton natans). Sampling is carried out upstream, downstream and half 
way the stretch on a monthly base. In each of these cross-sections, the amount of macrophytes is determined by taking samples every meter, at the same position were the discharge measurements are carried out. First the fresh weight $\left[\mathrm{g} / \mathrm{m}^{2}\right]$ of the plants is defined, afterward also the dry weight $\left[\mathrm{g} / \mathrm{m}^{2}\right]$ is postulated. The sampling of the macrophytes is carried out with a sampler as described in (Marshall and Lee [5]). This instrument has no moving parts, its primary components are a cutting blade fixed to the base of a vertical shaft to shear off plant stems at the substrate surface, and a collection rake to allow retrieval of the freed vegetation. The sampler is well suited for the measurements in this study, because a large variety of macrophytes over a range of conditions can be sampled, while possessing the design features of prime importance: lightweight, low cost and easily used.

\subsection{Femme environment}

Calculation are performed making use of software developed in 'Femme' ('a Flexible Environment for Mathematically Modelling the Environment') is developed by NIOO (Netherlands Institute of Ecology) (Soetaert et al. [6]). It is a modelling environment for the development and application of ecological time dependent processes by use of numerical integration in the time of differential equations. The program is written in Fortran. 'Femme' consists of a wide range of numerical calculations and model manipulations (as integration functions, forcing functions, linking to observed data, calibration possibilities, etc.). These technical possibilities allow the user to focus on the scientific part of the model without the confrontation with real programming linked problems.

'Femme' is focused on ecosystem modelling, is open source (no black box) and has a modular hierarchical structure (implementation of different modules). What was missing up till now was the implementation of a hydrodynamic surface water model to couple ecology and surface water each timestep. For the study of the interaction of ecological processes and flow, a realistic modelling of the surface water flow is necessary. In this study, a one dimensional hydrodynamic model for surface water flow based on the solution of the SaintVenant equations has been implemented in 'Femme'.

\section{Biomass influence on the resistance coefficient}

\subsection{Manning roughness coefficient}

The measured discharges and stages are used for the calculation of the roughness coefficient of the stretch, making use of the Bresse equation or the Manning equation. In steady state conditions (permanent flow) and assuming uniform flow, the energy slope is equal to the bottom slope and discharge, stage and Manning coefficient are linked directly by Manning's equation (Chow et al. [7]). In case of non-uniform permanent flow, Bresse equation is used to calculate the Manning coefficient. 


\subsection{Biomass distribution and the Manning coefficient}

A positive correlation between the biomass and the Manning coefficient was found by (Brooker et al. [8]) and mentioned in (Viaene and Vereecken [9]). For all measurements carried out over almost three years, the amount of macrophytes was determined and the Manning coefficient was calculated from the Bresse equation. The relation between biomass and Manning coefficient is clear. Low values for both are seen during winter (November to April), high values during spring and summer (June to September). More biomass results in a higher Manning coefficient (De Doncker et al. [10]). An exponentional curve is fitted to the values of biomass and Manning coefficient in Figure 2. Presence of vegetation increases the roughness and decreases the section and by this raises also the water level for the same discharge value.

\subsection{Relation between discharge and the Manning coefficient}

As the vegetation only covers part of the cross section, it is clear that with increasing discharge, and by this increasing water level, the relative influence of the biomass will become smaller. Figure 2 depicts the link between discharge and Manning coefficient as calculated from the Bresse equation, based on the measured data in the Aa between September 2004 and May 2007.

\subsection{Coaxial relation between the Manning coefficient, biomass and discharge}

The Manning coefficient is linked to the discharge (Fig. 1) and related to the biomass (Fig. 2). The relation Manning coefficient - discharge has an $\mathrm{R}^{2}$ value of 0.72 , while the relation between biomass and Manning coefficient agrees with $\mathrm{R}^{2}$ $=0.77$. The relation between these three parameters is expressed by (Eq. (3)) (De Doncker et al. [11]).

$$
n=0.169+\frac{0.1568}{Q}-0.1593 \exp (-0.0047 * \text { biomass })
$$

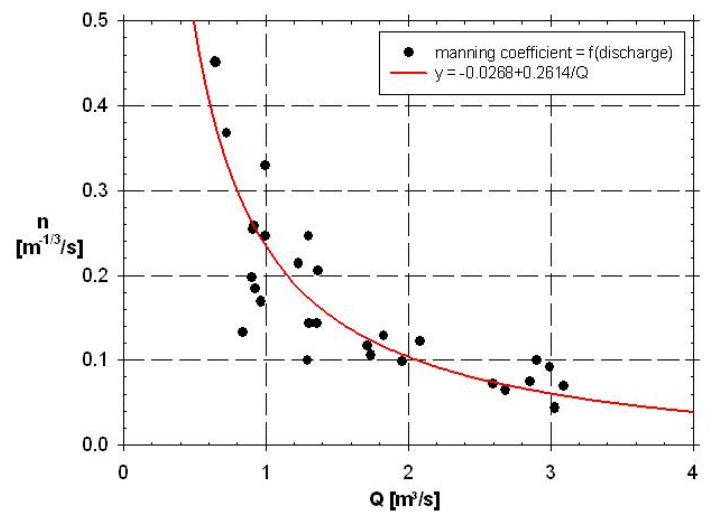

Figure 1: Correlation between discharge and the Manning coefficient in the river Aa from September 2004 to May 2007. 


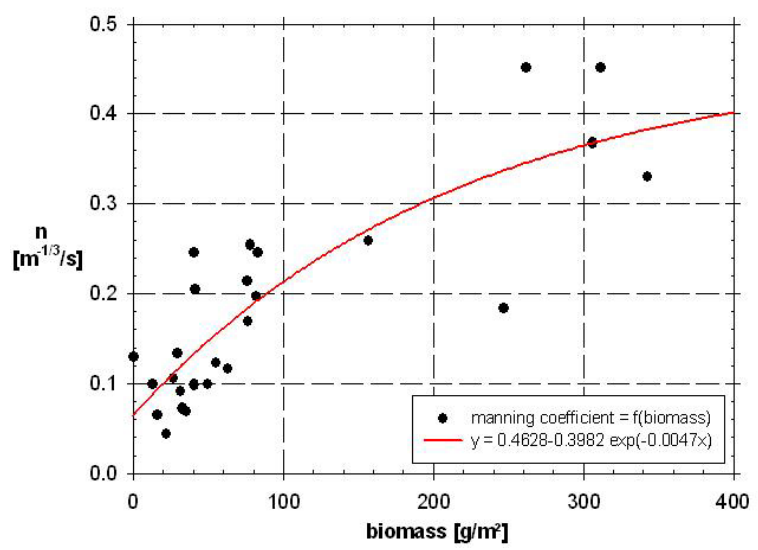

Figure 2: Exponentional correlation between biomass and the Manning coefficient in the river Aa from September 2004 to May 2007.

\section{Calculation results}

\subsection{Steady state conditions}

Due to vegetation and the consequential influence of backwater, the friction slope $S_{\mathrm{f}}$ of a river stretch can vary extremely, so the Manning coefficient has to be calculated using the Bresse equation. Figure 3 and Figure 4 show the situation in a theoretical stretch of $5000 \mathrm{~m}$. The cross-section is rectangular and has a bottom width of $12.0 \mathrm{~m}$. There is no slope along the stretch and the bottom level is $8.89 \mathrm{~m}$. The accuracy of the 'Femme' model in both steady and unsteady conditions is checked by comparing some results with the Hec-Ras model (Hydrologic Engineering Center [12]), which is a one dimensional code, also based on the solution of the Saint-Venant equations. Both models give the same values and Hec-Ras has already proven his worth, it demonstrates that the 'Femme' model returns good and reliable results.

In Figure 3, two cases are considered, a Manning coefficient of $0.1 \mathrm{~m}^{-1 / 3} / \mathrm{s}$, which corresponds with the values in the winter for the river Aa and a Manning coefficient of $0.4 \mathrm{~m}^{-1 / 3} / \mathrm{s}$ (spring and summer values). The Manning coefficient is up to 9 times higher in spring when there is wealthy vegetation (De Doncker et al. [9]). Starting from the same downstream water level $(10.20 \mathrm{~m})$ and using a discharge of $1 \mathrm{~m}^{3} / \mathrm{s}$, the upstream water level is calculated for both values of $\mathrm{n}$. In spring, a value of $11.25 \mathrm{~m}$ for the upstream water level is calculated, while $10.35 \mathrm{~m}$ is obtained in winter; this is a difference of $0.90 \mathrm{~m}$ due to the presence of vegetation.

Figure 4 shows the influence of the discharge on the energy slope $\mathrm{S}_{\mathrm{f}}$. For three different values of the discharge $\left(0.5 ; 1\right.$ and $\left.1.5 \mathrm{~m}^{3} / \mathrm{s}\right)$, the water surface profile is calculated. The Manning coefficient is kept constant at $0.1 \mathrm{~m}^{-1 / 3} \mathrm{~s}$. It is shown that tripling the discharge results in an increase of the water level of only $0.26 \mathrm{~m}\left(10.24 \mathrm{~m}\right.$ for the lowest discharge, $10.35 \mathrm{~m}$ for $\mathrm{Q}=1 \mathrm{~m}^{3} / \mathrm{s}$ and 10.50 for 
the highest value of $Q$ ). So, the impact of the vegetation on $S_{f}$ is much bigger and explains why dangerous situations may occur with regard to inundation during summer floods.

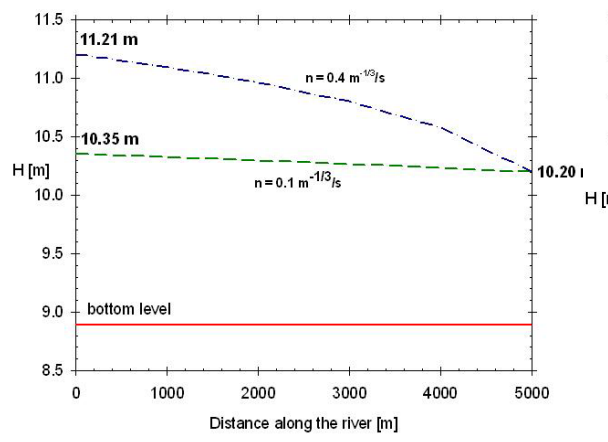

Figure 3: Backwater influence of the Manning coefficient on the water level for a given discharge.

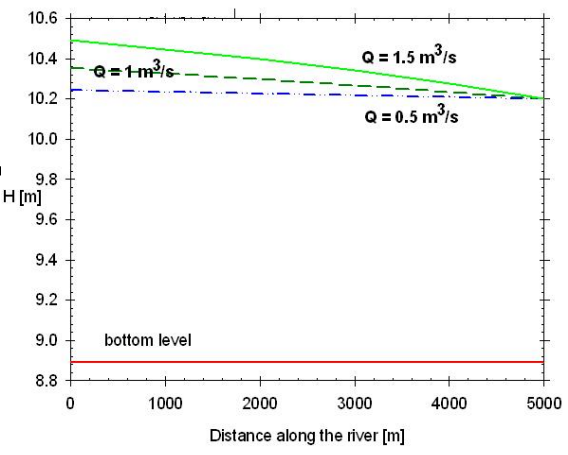

Figure 4: Backwater influence of the discharge on the water level for a given amount of vegetation.

\subsection{Unsteady state conditions}

Here, the impact of a variable resistance coefficient on the stream flow is illustrated. A flood wave, registered in the studied stretch of the river Aa, in the period from August $12^{\text {th }}$ to August $19^{\text {th }}(2005)$, is used as upstream boundary condition for the calculation (Qupstream). Downstream boundary condition is the registered water level at the downstream weir (Zdownstream). The studied stretch has a length of $5000 \mathrm{~m}$, a rectangular cross section and a bottom width of $12.0 \mathrm{~m}$. The bottom level is $8.89 \mathrm{~m}$.

Fig. 5 and Fig. 6 depict the boundary conditions and the calculated results for Qdownstream and Zupstream for two values of the Manning coefficient: in winter conditions $\left(n=0.1 \mathrm{~m}^{-1 / 3} \mathrm{~s}\right)$ and in summer conditions $\left(n=0.4 \mathrm{~m}^{-1 / 3} \mathrm{~s}\right)$. The variation, with the Manning coefficient, of the downstream discharge is limited, but it is clear that the upstream water level (Zupstream) is strongly influenced by the dense vegetation growth during summer. With increasing values of the Manning coefficient, the downstream discharge peak shows a small time lag and a substantial attenuation.

The river banks are indicated in Figs. 6 and 7. For low vegetation growth, the peak discharge and corresponding water level cause no problems. For values of the Manning coefficient larger than $0.205 \mathrm{~m}^{-1 / 3 \mathrm{~s}}$ (Fig. 7), the river banks $(11.6 \mathrm{~m})$ will be too low for the peak discharge and neighbouring areas will inundate. Therefore, study of the roughness of the river, including all determining parameters, is important. 


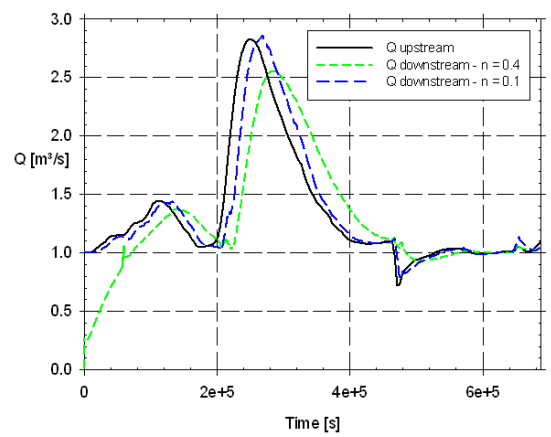

Figure 5: Boundary conditions Qupstream and calculated Qdownstream for $\mathrm{n}=0.4$ $\mathrm{m}^{-1 / 3}$.s and $\mathrm{n}=0.1 \mathrm{~m}^{-1 / 3} \mathrm{~s}$.

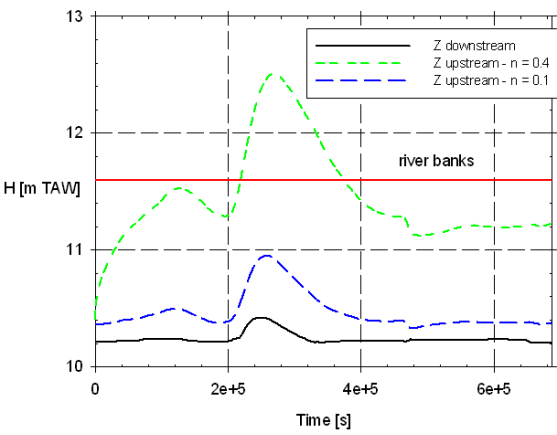

Figure 6: Boundary conditions Zdownstream and calculated Zupstream for $\mathrm{n}=0.4 \mathrm{~m}^{-1 / 3} \cdot \mathrm{s}$ and $\mathrm{n}=0.1 \mathrm{~m}^{-1 / 3} \mathrm{~s}$.

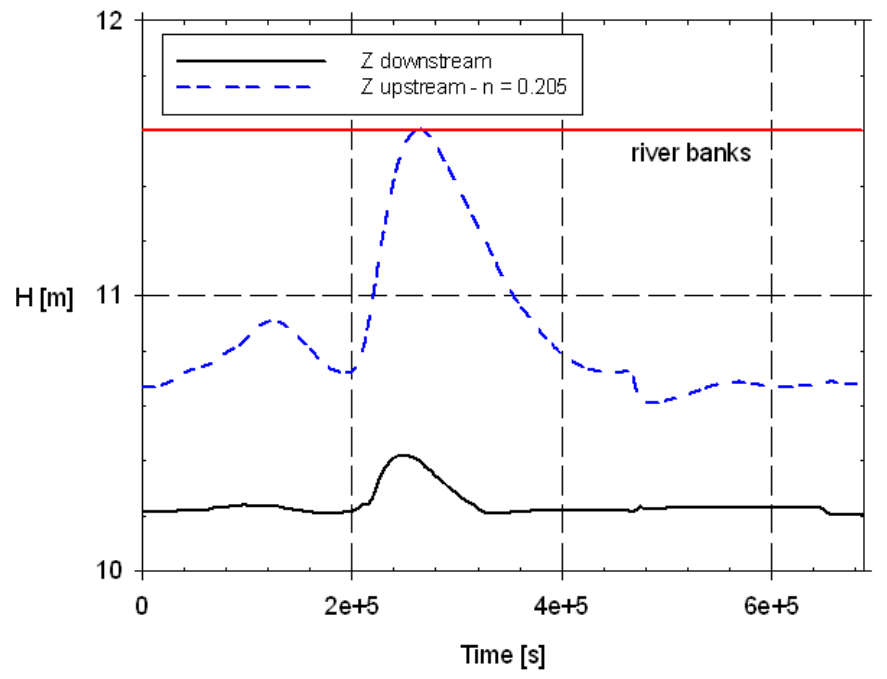

Figure 7: Upstream and downstream water level of the flood wave for $\mathrm{n}=0.205 \mathrm{~m}^{-1 / 3} \mathrm{~s}$, with indication of the river bank.

\section{Conclusion}

In this paper, the influence of aquatic vegetation on hydraulic characteristics in rivers is studied. Over the year, the amount of vegetation is linked to the seasonal cycle. The combination of a wealthy vegetation growth and summer storms can cause flood problems. 
A well-considered integrated river management needs to balance the requirements from the ecosystem with regard to water quality and the need for a safe flood protection policy. For a stretch of the river Aa, the correlation between discharge, biomass in the river and the resistance coefficient is demonstrated based on field measurements and hydraulic modelling. Calculation results show the influence of the resistance on both flow and water levels. Taking into account the environmental conditions (living area, agricultural land, etc.), peak values of the discharge have to be reduced e.g. for safety reasons. Therefore, a sound vegetation control policy can contribute to control flood water levels while at the same time guaranteeing the quality of the ecosystem.

\section{Acknowledgements}

This research is funded by the FWO (Fund for Scientific Research) - Flanders (G.0306.04). It is part of the multidisciplinary research project 'A fundamental study on exchange processes in river ecosystems' (University of Antwerp, Vrije Universiteit Brussel, Ghent University, 2004 - 2007). The overall objective is to study the physical and biological exchange processes in margins and inundation areas of water courses and how their interactions determine the exchange of water, dissolved compounds and particulate matter.

Thanks to Mr. Martin Van Daele and Mr. Stefaan Bliki for their assistance with the discharge measurements.

Also thanks to the Hydrological Information Centre of Flanders Hydraulics Research (HIC, Mr. E. Cornet) for providing the discharge and water level data of the river Aa.

\section{References}

[1] Vereecken, H., Baetens, J., Viaene, P., Mostaert, F. and Meire, P., Ecological management of aquatic plants: effects in lowland streams, Hydrobiologia, 2006.

[2] Aminal, De Kleine Nete, computer modelling as a method, high water control as a target (in Dutch) - computermodellering als methode, hoogwaterbeheer als doel. Grontmij Belgroma nv, in order of Aminal, 2004.

[3] NVVE, Waterplanten als graadmeters voor de ecologische toestand van het water: doel, referentie en beoordeling. Nederlands-Vlaamse Vereniging voor Ecologie - Werkgroep Water-en Oeverplanten, 2003.

[4] Herschy, R. (Ed.), Hydrometry: principles and practices. Wiley Interscience Publication. ISBN 0471996491, 1978.

[5] Marshall, T. and Lee, P., An inexpensive and lightweight sampler for the rapid collection of aquatic macrophytes. Journal of Aquatic Plant Management (32), 77-79, 1994.

[6] Soetaert, K. et al., Femme, a flexible environment for mathematically modeling the environment. Manuals, 2004.

[7] Chow, VT., Maidment, DR. and Mays, LW., Applied Hydrology, 1988. 
[8] Brooker, M., Morris, D. and Wilson, C., Plant flow relationships in the River Wye catchment. In European Weed Research Society $5^{\text {th }}$ International Symposium on Aquatic Weeds, 63-70, 1978.

[9] Viaene, P. and Vereecken, H., Stromingsweerstand tengevolge van waterplanten. Technical report Flanders Hydraulics. Rapport Ministerie van de Vlaamse Gemeenschap, Departement Leefmilieu en Infrastructuur, Administratie Milieu, Land- en Waterbeheer, Afdeling Water, Model 566, 2001.

[10] De Doncker, L., Troch, P., Verhoeven, R. Determination of the Manning Roughness Coefficient influenced by Vegetation in the River Aa and Biebrza River. In review, 2007.

[11] De Doncker, L., Troch, P., Verhoeven, R., Desmet, N., Meire, P., Seuntjes, $P$. relation between resistance characteristics due to aquatic weed growth and the hydraulic capacity of the river Aa. In review, 2007.

[12] Hydrologic Engineering Center, HEC-RAS River Analysis System, Version 3.1.3, US Army Corps of Engineers, 2004, http://www.hec.usace. army.mil/. 